\title{
Golimumab in Patients with Active Rheumatoid Arthritis Despite Methotrexate Therapy: Results Through 2 Years of the GO-FORWARD Study Extension
}

\author{
Edward C. Keystone, Mark C. Genovese, Stephen Hall, Pedro C. Miranda, Sang-Cheol Bae, \\ William Palmer, Zhong Wu, Stephen Xu, and Elizabeth C. Hsia
}

ABSTRACT. Objective. To assess the longterm efficacy and safety of golimumab in patients with active rheumatoid arthritis (RA) despite methotrexate (MTX) therapy.

Methods. We randomized 444 RA patients with inadequate response to MTX (3:3:2:2) to placebo + MTX (Group 1), golimumab $100 \mathrm{mg}+$ placebo (Group 2), golimumab $50 \mathrm{mg}+$ MTX (Group 3), or golimumab $100 \mathrm{mg}+$ MTX (Group 4). Subcutaneous golimumab/placebo was injected every 4 weeks. Patients could escape early (Group 1 added golimumab 50 mg, Group 2 added MTX, Group 3 increased golimumab to $100 \mathrm{mg}$, Group 4 continued $100 \mathrm{mg}$ ) based on Week 16 swollen and tender joint counts. From Week 24, Group 1 patients received golimumab $50 \mathrm{mg}+$ MTX. After the Week 52 database lock, patients in the longterm extension received golimumab 50-100 mg \pm MTX. Coprimary endpoints [Week 14 American College of Rheumatology (ACR)20, Week 24 Health Assessment Questionnaire Disability Index (HAQ-DI)] and Week 52 findings have been published; 2-year findings (observed data by randomized group, no imputation) are presented.

Results. Of 444 randomized patients, 392 continued from Week 52 (Group 1: $\mathrm{n}=116$, Group 2: $\mathrm{n}=$ 116, Group 3: $\mathrm{n}=84$, Group 4: $\mathrm{n}=76$ ). Clinical improvement was maintained through Week 104; $\sim 75 \%$ and $72 \%$ of patients randomized to golimumab $50 \mathrm{mg}+$ MTX and $100 \mathrm{mg}+$ MTX achieved ACR20 response, respectively. The majority [88\% (105/120)] of golimumab + MTX-treated patients with Week 24 HAQ-DI improvement $\geq 0.25$ maintained improved physical function through Week 104. Group 1 patients with delayed golimumab treatment exhibited more Week 104 radiographic progression (mean change score $=1.15$ ) than golimumab + MTX-randomized patients (0.52). Incidences of serious infections were 2.24, 4.77, 5.78/100 patient-years of followup for golimumab $50 \mathrm{mg}+$ MTX, $100 \mathrm{mg}+$ placebo, and $100 \mathrm{mg}+$ MTX, respectively.

Conclusion. Clinical improvement was maintained and no new safety signals were identified with 2 years of golimumab + MTX. Golimumab efficacy and safety, including serious infections, will continue to be monitored through 5 years (Clinical Trial No. NCT00264550). (First Release May 15 2013; J Rheumatol 2013;40:1097-103; doi:10.3899/jrheum.120584)

Key Indexing Terms:

TUMOR NECROSIS FACTOR ANTAGONIST SAFETY

\section{LONGTERM EFFICACY RHEUMATOID ARTHRITIS}

From the Immunology and Rheumatology departments, University of Toronto and Mount Sinai Hospital, Toronto, Ontario, Canada; Immunology and Rheumatology departments, Stanford University, Palo Alto, California, USA; Rheumatology, Cabrini Medical Centre, Malvern, Victoria, Australia; Rheumatology, Universidad de Chile and Hospital San Juan de Dios, Santiago, Chile; Department of Rheumatology, Hanyang University Hospital for Rheumatic Diseases, Seoul, Korea; Rheumatic Diseases, Westroads Medical Group, Omaha, Nebraska, USA Clinical Research and Biostatistics, Janssen Research and Development LLC, Spring House, Pennsylvania, USA; and Rheumatology, University of Pennsylvania School of Medicine, Philadelphia, Pennsylvania, USA.

Funded by Janssen Research and Development LLC, a Johnson \& Johnson pharmaceutical company, and Merck/Schering-Plough.

Dr. Genovese has received grant support from, and served as a consultant to, Janssen/Johnson \& Johnson. Dr. Keystone has received consulting fees, speaking fees, and/or research grants from Abbott Laboratories, Amgen Inc., AstraZeneca Pharmaceuticals LP, Bristol-Myers Squibb, F. Hoffmann-LaRoche Ltd., Genentech Inc., Janssen/Johnson \& Johnson, Merck/Schering-Plough, Novartis Pharmaceuticals Corporation, Pfizer

\begin{abstract}
Pharmaceuticals, UCB, and Wyeth Pharmaceuticals. Dr. Bae has received consulting fees and/or research grants from Abbott Korea, Eisai Korea, MSD Korea, Pfizer, Schering-Plough Korea, and Wyeth Korea. Drs. Hall, Miranda, and Palmer have received research grant support from Janssen/Johnson \& Johnson. Drs. Hsia and Wu and S. Xu are employees of Janssen, a Johnson \& Johnson company. Drs. Hsia and S. Xu own Johnson \& Johnson stock and/or stock options.

E.C. Keystone, MD, FRCPC, Professor of Medicine, Immunology and Rheumatology, University of Toronto and Mount Sinai Hospital; M.C. Genovese, MD, Professor of Medicine, Immunology and Rheumatology, Stanford University; S. Hall, MD, Professor of Medicine, Rheumatology, Cabrini Medical Centre; P.C. Miranda, MD, Professor of Medicine, Rheumatology, Universidad de Chile and Hospital San Juan de Dios; S-C. Bae, MD, Professor of Medicine, Department of Rheumatology, Hanyang University Hospital for Rheumatic Diseases; W. Palmer, MD, FACR, Rheumatic Diseases, Westroads Medical Group; Z. Wu, PhD, Biostatistical Manager; $S$. Xu, MS, Biostatistical Manager, Biostatistics, Janssen Research and Development LLC; E.C. Hsia, MD, Director of Clinical Research, Janssen Research and Development LLC,
\end{abstract}


and Rheumatology, University of Pennsylvania School of Medicine. Address correspondence to Dr. E.C. Keystone, Mount Sinai Hospital, 60 Murray Street, Room 2-006, Toronto, Ontario M5G 1X5, Canada. E-mail:edkeystone@mtsinai.on.ca

Full Release Article. For details see Reprints/Permissions at jrheum.org Accepted for publication March 20, 2013.

Golimumab is a human monoclonal antibody to tumor necrosis factor- $\alpha$ (TNF- $\alpha$ ), indicated for the treatment of rheumatoid arthritis (RA). In patients with active RA despite methotrexate (MTX) therapy, the addition of golimumab in the phase III, randomized, placebo-controlled GO-FORWARD study reduced the signs and symptoms of $\mathrm{RA}^{1}$. Clinical response was maintained through 1 year, with 77\%-91\% of patients exhibiting American College of Rheumatology (ACR)20 response at Week 24 and Week 52, and the golimumab safety profile appeared consistent with those of other TNF antagonists ${ }^{2}$. Minimal radiographic progression was observed in all groups. Although differences in modified Sharp score changes between groups were not statistically significant ${ }^{3}$, golimumab + MTX significantly improved magnetic resonance imaging-detected synovitis and osteitis (predictors of future structural damage) versus placebo + MTX through Week 244. We now present findings through Week 104 of the GO-FORWARD study, describing an additional year of golimumab efficacy and safety monitoring.

\section{MATERIALS AND METHODS}

Details of the GO-FORWARD (NCT00264550) trial have been reported ${ }^{1,2}$ The study was conducted according to the Declaration of Helsinki and good clinical practices. The protocol was reviewed and approved by each site's institutional review board or ethical committee, and informed consent was obtained prior to any study-related procedures. Patients with active RA $^{3}$ despite stable MTX therapy (15-25 mg/week) for $\geq 4$ weeks were randomized 3:3:2:2 to placebo injections/MTX capsules (Group 1), golimumab $100 \mathrm{mg}$ injections plus placebo capsules (Group 2), golimumab $50 \mathrm{mg}$ injections plus MTX capsules (Group 3), or golimumab 100 mg injections plus MTX capsules (Group 4). All injections were administered subcutaneously (SC) every 4 weeks. Patients in Groups 1, 3, and 4 continued MTX; patients in Group 2 received sham MTX.

At Week 16, patients in Groups 1-3 with $<20 \%$ improvement in tender and swollen joint counts entered early escape (EE) and had study medication adjusted in a double-blind manner. Patients in Group 1 replaced placebo with golimumab $50 \mathrm{mg}$ while continuing MTX; those in Group 2 replaced oral placebo with MTX (at the stable prescreening dose) while continuing golimumab $100 \mathrm{mg}$; and those in Group 3 increased golimumab from $50 \mathrm{mg}$ to $100 \mathrm{mg}$ while continuing MTX. Patients in Group 4 had no treatment adjustment.

At Week 24, patients in Group 1 who were still receiving placebo initiated blinded golimumab $50 \mathrm{mg}$ injections. Patients in Groups 2, 3, and 4 continued their original or EE-modified treatment. Blinded treatment continued every 4 weeks through Week 52 .

After Week 52, patients entered the longterm extension (LTE), during which the blind was broken after all patients completed the visit scheduled for Week 52 and the Week 52 database was locked. During the LTE, at the investigator's discretion, the golimumab dose could be increased from 50 $\mathrm{mg}$ to $100 \mathrm{mg}$ and MTX doses could be adjusted or added. LTE visits were scheduled for every 12 weeks. The LTE continues through Week 268, and findings through Week 104 are reported here.
Clinical response was assessed using ACR criteria $^{5}$ and European League Against Rheumatism (EULAR) 28-joint Disease Activity Scores using C-reactive protein (DAS28-CRP) ${ }^{6,7}$. A DAS28-CRP score $<2.6$ indicated clinical remission ${ }^{8}$. The Health Assessment Questionnaire Disability Index (HAQ-DI) ${ }^{9}$ was used to assess physical function. Radiographs of both hands and both feet were obtained at baseline and Weeks 24, 52, and 104. Results for Reading Session 1 (baseline, Week 24 , and Week 52) have been published ${ }^{10}$. Results from Reading Session 2 (baseline, Week 52, and Week 104) are now reported. Centrally digitized images were scored, using the Sharp/van der Heijde Score (SHS $)^{11}$, as described ${ }^{10}$. Safety was assessed by reported adverse events (AE). The incidences of death, serious infection, and malignancy were calculated per 100 patient-years to account for differences in followup between treatment groups. Observed incidences of malignancy were compared with those expected in the general US population per the Surveillance, Epidemiology, and End Results (SEER) database ${ }^{12}$. Standardized incidence ratios were calculated as "observed" (GO-FORWARD) divided by "expected" (SEER database) cases of malignancy, and exact 95\% CI were determined. Nonmelanoma skin cancer is not included in the SEER database and thus is not included in the comparative analyses. Antibodies to golimumab were assessed using a bridging immunoassay ${ }^{13}$ on blood samples collected prior to administration of study agent.

Observed clinical efficacy data through Week 104 were summarized by randomized treatment group (despite any protocol-mandated treatment changes) using descriptive statistics; missing data were not imputed. Patients with baseline and $\geq 1$ followup SHS were included in radiographic analyses. Patients who discontinued treatment prematurely had images obtained at discontinuation; these scores were carried forward to Week 104 Radiographic scores were not linearly extrapolated. Patients receiving $\geq 1$ SC injection were included in safety summaries according to actual treatment received.

\section{RESULTS}

Patient disposition and baseline characteristics. Data for this report were collected between December 2005 and March 2009. All 444 randomized patients received $\geq 1$ dose of study agent, and 392 patients $(88.3 \%)$ continued in the study from Week 52. At Week 16, 92 of 355 patients eligible for dose adjustment (25.9\%) met the EE criteria and had their study treatment adjusted (Figure 1). During the LTE, 49 patients had the golimumab dose increased to $100 \mathrm{mg}$. Among these 49 patients, 23 (46.9\%) demonstrated a state of low disease activity (DAS28-CRP score <3.2) at the time of dose escalation. By Week 104, 90 patients $(20.3 \%)$ discontinued SC therapy, including 44 patients (9.9\%) who discontinued treatment because of AE; 18 patients $(4.1 \%)$ because of unsatisfactory therapeutic effect; and 28 patients $(6.3 \%)$ because of other reasons such as withdrawal of consent, loss to followup, or protocol violation. Baseline patient and disease characteristics have been reported ${ }^{1}$.

Clinical response. As reported ${ }^{1}$, golimumab + MTX was significantly more effective than MTX for most assessments of clinical response, including the primary study endpoint of Week 14 ACR20 response rates [55.6\% (99/178) vs $33.1 \%$ (44/133), respectively; $p<0.001]$. Among patients continuing treatment, the proportions of patients achieving ACR20 response at Week 104 were $74.7 \%(62 / 83)$ and $71.6 \%$ (48/67) for Group 3 and Group 4, respectively. Median improvements in swollen and tender joint counts at 


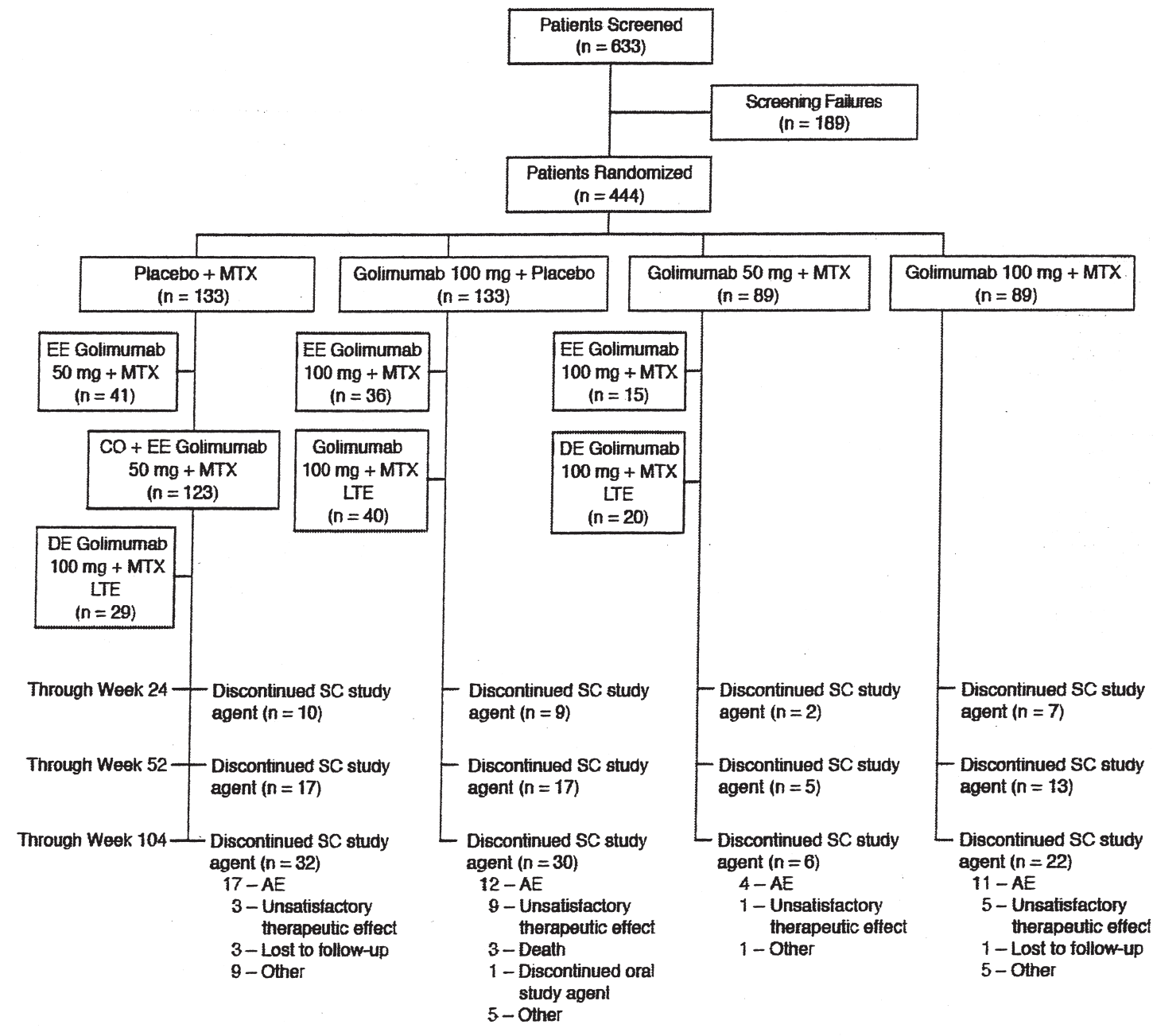

Figure 1. Patient disposition through Week 104; randomized patients. MTX: methotrexate; EE: early escape; CO: crossover; LTE: longterm extension; DE: dose escalation; SC: subcutaneous; AE: adverse event.

Week 104 were -10.0 and -16.5 , respectively, in golimumab + MTX-randomized patients (Table 1), representing about $90 \%$ improvement from baseline.

Golimumab + MTX was also significantly more effective than MTX in the achievement of Week 24 EULAR/DAS28 response [74.2\% (132/178) vs $42.1 \%(56 / 133) ; \mathrm{p}<0.001]^{1}$. Among patients continuing treatment, $88.0 \%(73 / 83)$ and $91.0 \%(61 / 67)$ of patients in Group 3 and Group 4, respectively, achieved EULAR/DAS28 response at Week 104 (Table 1).

Physical function. Golimumab + MTX significantly improved Week 24 median HAQ scores $(-0.44$ vs -0.13 for MTX; $\mathrm{p}<0.001)^{1}$. Median improvements in HAQ at Week 104 (0.6 in Group 3, 0.4 in Group 4) yielded a median HAQ score of 0.6 at Week 104 (Table 1), representing about 57\% improvement from the baseline median score of $1.4^{1}$.

At Week 104, 72.3\% (60/83) and 73.1\% (49/67) of patients in Group 3 and Group 4, respectively, had $\geq$ 0.25-unit improvement from baseline in HAQ scores.
Among Week 24 HAQ responders, 86.7\% (52/60) and 88.3\% (53/60) of patients in Group 3 and Group 4, respectively, maintained improvement through Week 104 (Table 1).

Radiographic response. Mean changes from baseline in total SHS through Week 104 were small, particularly in patients randomized to golimumab + MTX (0.52). Group 1 patients, whose golimumab treatment was delayed, exhibited more progression at Week 104 (mean change $=$ 1.15; Table 1).

Adverse events. Through Week 104, common AE included upper respiratory tract infection, cough, nasopharyngitis, bronchitis, and headache. AE led to discontinuation of SC study agent in $41(9.4 \%)$ golimumab-treated patients $(9.8 \%$ in $100 \mathrm{mg}+$ placebo group, $6.6 \%$ in $50 \mathrm{mg}+$ MTX group, $6.3 \%$ in $100 \mathrm{mg}+$ MTX group; Table 2).

Ninety-eight (22.6\%) golimumab-treated patients had serious AE (SAE). Serious infections were the most common SAE (6.7\% of golimumab-treated patients). The incidences of serious infections per 100 patient-years of

$$
\text { Personal non-commercial use only. The Journal of Rheumatology Copyright ( }) \text { 2013. All rights reserved. }
$$


Table 1. Summary of clinical and radiographic response through Week 104. Data shown are change from baseline or number (\%) of patients with response unless noted otherwise. Data are summarized by randomized treatment group.

\begin{tabular}{|c|c|c|c|c|c|}
\hline & $\begin{array}{l}\text { Group } 1 \\
\text { Placebo + } \\
\text { MTX }^{1}\end{array}$ & $\begin{array}{c}\text { Group } 2 \\
\text { Golimumab } \\
100 \mathrm{mg}+\text { Placebo }^{2}\end{array}$ & $\begin{array}{c}\text { Group } 3 \\
\text { Golimumab } \\
50 \mathrm{mg}+\mathrm{MTX}^{3}\end{array}$ & $\begin{array}{c}\text { Group 4 } \\
\text { Golimumab } \\
100 \mathrm{mg}+\text { MTX }\end{array}$ & $\begin{array}{l}\text { Combined } \\
\text { Golimumab + } \\
\text { MTX }\end{array}$ \\
\hline ACR20 response & $68 / 104(65.4 \%)$ & $74 / 106(69.8 \%)$ & $62 / 83(74.7 \%)$ & $48 / 67(71.6 \%)$ & $110 / 150(73.3 \%)$ \\
\hline At Wk 52 and Wk 104 & $57 / 73(78.1 \%)$ & $59 / 69(85.5 \%)$ & $52 / 63(82.5 \%)$ & $40 / 46(87.0 \%)$ & $92 / 109(84.4 \%)$ \\
\hline ACR50 response & $38 / 104(36.5 \%)$ & $49 / 106(46.2 \%)$ & $50 / 83(60.2 \%)$ & $34 / 67(50.7 \%)$ & $84 / 150(56.0 \%)$ \\
\hline At Wk 52 and Wk 104 & $16 / 25(64.0 \%)$ & $16 / 23(69.6 \%)$ & $17 / 21(81.0 \%)$ & $20 / 28(71.4 \%)$ & $37 / 49(75.5 \%)$ \\
\hline \multicolumn{6}{|l|}{ Swollen joint count } \\
\hline Median (IQR) joint count & $2.0(0.0,5.0)$ & $2.0(0.0,6.0)$ & $2.0(0.0,6.0)$ & $1.0(0.0,4.0)$ & $1.5(0.0,4.0)$ \\
\hline Median (IQR) change & $-8.5(-13.0,-5.5)$ & $-8.0(-14.0,-5.0)$ & $-9.0(-19.0,-5.0)$ & $-10.0(-15.0,-5.0)$ & $-10.0(-15.0,-5.0)$ \\
\hline \multicolumn{6}{|l|}{ Tender joint count } \\
\hline Median joint count & $3.0(1.0,9.5)$ & $3.0(1.0,9.0)$ & $3.0(0.0,12.0)$ & $2.0(0.0,9.0)$ & $3.0(0.0,9.0)$ \\
\hline Responder (Good + Moderate) & $89 / 102(87.3 \%)$ & $91 / 105(86.7 \%)$ & $73 / 83(88.0 \%)$ & $61 / 67(91.0 \%)$ & $134 / 150(89.3 \%)$ \\
\hline At Wk 52 and 104 & $77 / 82(93.9 \%)$ & $80 / 90(88.9 \%)$ & $68 / 75(90.7 \%)$ & $56 / 59(94.9 \%)$ & $124 / 134(92.5 \%)$ \\
\hline Remission $(<2.6)$ & $42 / 102(41.2 \%)$ & $43 / 105(41.0 \%)$ & $39 / 83(47.0 \%)$ & $35 / 67(52.2 \%)$ & $74 / 150(49.3 \%)$ \\
\hline At Wk 52 and Wk 104 & $22 / 31(71.0 \%)$ & $22 / 32(68.8 \%)$ & $24 / 34(70.6 \%)$ & $25 / 33(75.8 \%)$ & $49 / 67(73.1 \%)$ \\
\hline \multicolumn{6}{|l|}{ HAQ-DI score } \\
\hline Median (IQR) score & $0.9(0.3,1.4)$ & $0.5(0.1,1.1)$ & $0.5(0.3,1.4)$ & $0.6(0.3,1.3)$ & $0.6(0.3,1.4)$ \\
\hline Median (IQR) change & $0.4(0.0,0.7)$ & $0.5(0.1,1.0)$ & $0.6(0.1,1.0)$ & $0.4(0.1,0.9)$ & $0.5(0.1,0.9)$ \\
\hline$\geq 0.25$-unit improvement & $64 / 104(61.5 \%)$ & $75 / 106(70.8 \%)$ & $60 / 83(72.3 \%)$ & $49 / 67(73.1 \%)$ & $109 / 150(72.7 \%)$ \\
\hline At Wk 24 and Wk 104 & $43 / 47(91.5 \%)$ & $50 / 57(87.7 \%)$ & $52 / 60(86.7 \%)$ & $53 / 60(88.3 \%)$ & $105 / 120(87.5 \%)$ \\
\hline At Wk 52 and Wk 104 & $56 / 68(82.4 \%)$ & $60 / 64(93.8 \%)$ & $57 / 63(90.5 \%)$ & $46 / 50(92.0 \%)$ & $103 / 113(91.2 \%)$ \\
\hline \multicolumn{6}{|l|}{ SHS-Total ${ }^{4,5}$} \\
\hline Mean (SD) change to Wk 104 & $1.15(4.41)$ & $1.87(5.77)$ & $0.51(3.32)$ & $0.54(3.49)$ & $0.52(3.39)$ \\
\hline
\end{tabular}

\footnotetext{
${ }^{1}$ Includes patients who escaped early at Week 16 or crossed over at Week 24 to receive golimumab $50 \mathrm{mg}+$ MTX or whose doses were escalated after Week 52 to receive golimumab $100 \mathrm{mg}+$ MTX. ${ }^{2}$ Includes patients who escaped early at Week 16 to receive golimumab $100 \mathrm{mg}+$ MTX or added MTX after Week 52. ${ }^{3}$ Includes patients who escaped early at Week 16 or whose doses were escalated after Week 52 to receive golimumab 100 mg + MTX. ${ }^{4}$ Includes patients with baseline SHS and $\geq 1$ SHS after Week 52. ${ }^{5}$ Missing imputation rules were applied. Within type (erosion, joint space narrowing) and region (hand, foot), if $\geq 50 \%$ of joint scores were imputed with worst-case scores because of procedure or injection, then change from baseline of this subscore was imputed with worst change score of type-by-region subscores among all other patients. * Change in SHS $\leq 0$. ACR: American College of Rheumatology; CRP: C-reactive protein; DAS28: Disease Activity Score using 28-joint count; HAQ-DI: Health Assessment Questionnaire (Disability Index); IQR: interquartile range; MTX: methotrexate; SHS: Sharp/van der Heijde Score.
}

followup were $2.24(95 \% \mathrm{CI} 0.90,4.62)$ and 5.18 (95\% CI $2.83,8.69)$ for $50 \mathrm{mg}+\mathrm{MTX}$ and $100 \mathrm{mg}+\mathrm{MTX}$, respectively, and 0.00 (95\% CI 0.00, 5.83) for placebo (Table 2). Two patients developed active tuberculosis through Week 104 (50 mg + MTX: tuberculosis pleurisy; 100 mg + MTX: peritoneal tuberculosis).

Two patients (100 mg + placebo) died through Week 52 (sepsis, hepatic failure $)^{1,2}$. The patient with hepatic failure experienced a complicated hospitalization including severe intraabdominal hemorrhage following liver biopsy. Two additional patients died through Week $104(100 \mathrm{mg}+$ placebo: complicated respiratory distress following acute pulmonary edema post-open cholecystectomy; $100 \mathrm{mg}+$
MTX: circulatory insufficiency), yielding overall incidences of 0.53 (95\% CI $0.15,1.37) / 100$ pt-yrs for golimumab versus $0.00(95 \%$ CI $0.00,5.83) / 100$ pt-yrs for placebo (Table 2).

Two placebo-treated [3.89 (95\% CI $0.47,14.05) / 100$ pt-yrs] and 14 golimumab-treated [1.87 (95\% CI 1.02, $3.13) / 100$ pt-yrs] patients had malignancy diagnosed through Week 104 (Table 2). Four patients (50 mg + MTX: $\mathrm{n}=2 ; 100 \mathrm{mg}+$ MTX: $\mathrm{n}=2$ ) had breast cancer, 1 patient (100 mg + MTX) had lymphoma, and 11 patients (placebo + MTX: $\mathrm{n}=2 ; 100 \mathrm{mg}+$ placebo: $\mathrm{n}=3 ; 50 \mathrm{mg}+$ MTX: $\mathrm{n}=4 ; 100 \mathrm{mg}+$ MTX: $\mathrm{n}=2$ ) had squamous and/or basal cell carcinoma (basal: $\mathrm{n}=6$, squamous: $\mathrm{n}=3$, squamous +

Personal non-commercial use only. The Journal of Rheumatology Copyright $(\subset$ 2013. All rights reserved. 
Table 2. Summary of key safety findings through Week 104. Data presented are number (\%) of patients unless specified otherwise.

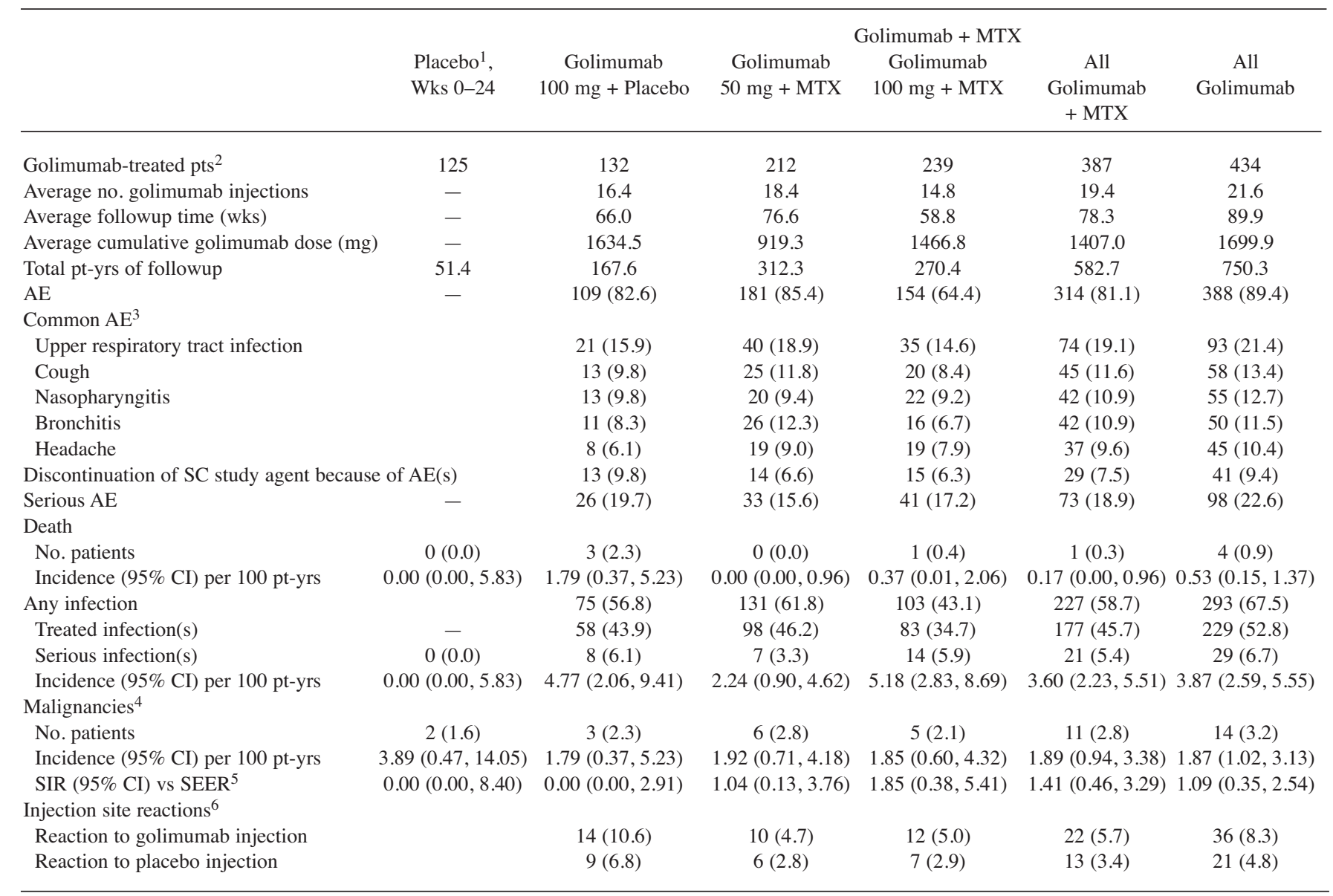

${ }^{1}$ Because of vast differences in length of followup for placebo versus golimumab treatment, incidence by length of followup is provided for AE of interest, i.e., death, serious infection, malignancy. ${ }^{2}$ Patients may appear in more than 1 column. Thus, treatment groups are not mutually exclusive. ${ }^{3}$ Absolute numbers and percentages of patients with 1 or more AE reported in $10 \%$ or more of golimumab-treated patients. The Medical Dictionary for Regulatory Activities (MedDRA) preferred terms are sorted by decreasing frequency in the "All Golimumab" group. ${ }^{4}$ Two (1.5\%) additional patients in the placebo + MTX group had malignancies through Week 52, yielding a total of 16 patients with malignancy. ${ }^{5}$ SIR: standardized incidence ratio, i.e., observed/expected incidences of malignancy (excluding nonmelanoma skin cancer). ${ }^{6}$ Injection site reactions were defined as any adverse reaction at a subcutaneous study agent injection site. MTX: methotrexate; pt-yrs: patient-years; SC: subcutaneous; SEER: Surveillance, Epidemiology and End Results; AE: adverse events.

basal: $\mathrm{n}=2$ ). For both death and malignancy, incidences by length of treatment/followup yielded overlapping $95 \% \mathrm{CI}$, suggesting no difference between the golimumab-treated patients treated through Week 104 and patients receiving placebo + MTX therapy through Week 24 (Table 2). Results of an additional analysis indicated that the incidence of malignancy (excluding nonmelanoma skin cancers) in patients receiving golimumab appeared to be similar to that expected in a general population based on the SEER database, because all 95\% CI were inclusive of 1 (Table 2).

Injection-site reactions occurred in $8.3 \%$ of golimumab-treated and $4.8 \%$ of placebo-treated patients, with higher incidences observed in patients receiving golimumab $100 \mathrm{mg}+$ placebo (10.6\%) than golimumab + MTX $(5.7 \%$; Table 2). Most reactions, mainly erythema, were mild. No injection-site reaction was serious, and 1 patient $(50 \mathrm{mg}+$ MTX) discontinued study agent because of moderate injection-site erythema. No golimumab-treated patient experienced an anaphylactic or serum sickness reaction through Week 104.

Antibodies to golimumab. Antibodies to golimumab were detected in $6.3 \%$ (27/428) of golimumab-treated patients at Week 104. Patients randomized to golimumab $100 \mathrm{mg}+$ placebo had a higher incidence of antibodies to golimumab $(13.1 \%)$ than patients who received MTX since Week 0 $(4.3 \%)$

\section{DISCUSSION}

Our results demonstrate that the majority of patients continuing treatment with golimumab + MTX experienced sustained, significant improvements in disease activity and physical function through Week 104. At Week 24, golimumab (50 mg and $100 \mathrm{mg}$ ) + MTX was significantly more effective than MTX monotherapy for most assess-

Personal non-commercial use only. The Journal of Rheumatology Copyright $\odot$ 2013. All rights reserved. 
ments of clinical response, including ACR20 response at Week 14, which was achieved by about half of golimumab + MTX-treated patients ${ }^{1}$. Among patients who continued golimumab treatment, about three-quarters achieved ACR20 response at Week 104. Also at Week 104, swollen and tender joint counts were improved by about $90 \%$, and about $50 \%$ of patients achieved DAS28-CRP remission (score <2.6). Patients receiving golimumab + MTX also showed sustained, significant improvements from baseline in functional status, as demonstrated by about $60 \%$ improvement in the HAQ score from baseline ${ }^{1}$. In addition, > $70 \%$ of golimumab + MTX-treated patients had clinically significant improvements in HAQ at Week 104, and most $(\geq 87 \%$ ) who achieved HAQ improvement $\geq 0.25$ at Week 24 maintained this clinically significant improvement at Week 104. Note that clinical and functional improvement observed at Week 52 was also observed at Week 104 in the vast majority of golimumab + MTX-treated patients (Table 1). As reported, radiographic progression through Week 24 was minimal in all groups, including the controls ${ }^{10}$. Consistent with these observations, mean changes from baseline in total SHS through Week 104 were small, particularly in patients randomized to golimumab + MTX.

Safety results observed among patients who continued treatment through 2 years were similar to those derived from earlier assessments ${ }^{1,2}$. While no new golimumab safety signals emerged, the higher incidence of serious infections with golimumab $100 \mathrm{mg}+$ MTX than with $50 \mathrm{mg}+$ MTX we observed was consistent with earlier reports of our study and reports from other studies of increased risk of serious infection with higher doses of golimumab ${ }^{14}$ and other TNF antagonists ${ }^{15,16}$. The higher incidence of serious infections in the $100 \mathrm{mg}+$ MTX group compared with the $50 \mathrm{mg}+$ MTX group appeared to be driven by events that occurred soon after initiation of golimumab, i.e., 4 serious infections occurred within the first 2 months in the $100 \mathrm{mg}+$ MTX group versus 1 such infection in the $50 \mathrm{mg}+$ MTX group. This finding is consistent with a hypothesis that the indiscriminate randomization process likely leads to the higher dose being given to patients who may not require it and that this may contribute to a higher incidence of serious infection with the higher dose than would be observed in clinical practice, where greater TNF inhibition can be more selectively applied. The START study of infliximab supports this concept ${ }^{15,17}$. In that study, patients who were randomized to $10 \mathrm{mg} / \mathrm{kg}$ had a higher incidence of serious infections, while those whose doses were escalated based on clinical response did not. Serious infections were similar in nature to those reported previously in this ${ }^{1,2}$ and other golimumab studies ${ }^{14}$. Despite testing performed at screening, 2 cases of active tuberculosis were observed through Week 104, both in areas with relatively higher background tuberculosis rates (Taiwan, Poland). These cases underscore the need for ongoing monitoring of patients receiving anti-TNF therapy for the onset of tuberculous infections ${ }^{18}$.

Through Week 104, 4 golimumab-treated patients died (sepsis, hepatic failure, complicated respiratory distress, circulatory insufficiency). The 2 patients who died prior to Week 52 (sepsis, hepatic failure) are described in previous reports $^{1,2}$. Two patients also died between Weeks 52 and 104. One patient underwent open cholecystectomy for cholelithiasis and developed acute pulmonary edema during the procedure. The patient's subsequent hospital course was complicated by hemothorax from subclavian puncture, and the patient eventually succumbed to complicated respiratory distress. The second patient died as a result of circulatory insufficiency. The patient was found dead at home 2 days after being discharged from the hospital for an RA flare. While the underlying cause of death remains unclear because no autopsy was performed, this patient had discontinued golimumab 7 weeks prior to death because of nonserious AE (infectious otitis and pharyngitis). Fourteen golimumab-treated patients had malignancies (breast: $\mathrm{n}=4$, lymphoma: $\mathrm{n}=1$, squamous/basal cell carcinoma: $\mathrm{n}=9$ ). When incidences of death and malignancy were assessed by length of treatment/followup, overlapping 95\% CI suggested no difference between the golimumab-treated patients at Week 104 and patients receiving placebo + MTX therapy through Week 24. Results of an additional analysis indicated that the incidence of malignancy (excluding nonmelanoma skin cancers) in patients receiving golimumab appeared to be similar to that expected based on the SEER database, i.e., all 95\% CI were inclusive of 1 (Table 2). It should be remembered that the SEER database is reflective of a general population and not patients with RA, who generally have worse overall health and are at increased risk of certain comorbidities and malignancies such as lymphoma.

Findings reported here are limited by several factors. First, given that no statistical inference testing was planned for the 2-year followup timepoint in the study, observed efficacy data are reported with no imputation of missing data. Therefore, response rates through 2 years could be higher owing to enrichment of the remaining study population with patients responding to treatment. However, most patients who discontinued by Week 104 did so because of $\mathrm{AE}$ (44 patients) or other generally administrative reasons (28 patients) and not because of lack of efficacy. As an additional limitation, the relatively short placebo-controlled period (6 months), with an early escape at Week 16 required for ethical reasons, makes comparisons between the active and placebo groups difficult, especially for safety analyses when examining the occurrence of rare safety events that accrue over time, such as malignancy and death.

The majority of patients continuing golimumab + MTX experienced significant improvements in RA signs and

Personal non-commercial use only. The Journal of Rheumatology Copyright @ 2013. All rights reserved. 
symptoms and physical function that were maintained, and exhibited only limited radiographic progression, through 2 years. No new golimumab safety signals were identified. Evaluation of longer-term efficacy and safety data, including the incidence of serious infections associated with the higher golimumab dose, for SC golimumab every 4 weeks in combination with MTX will continue through 5 years in these patients with an inadequate response to MTX.

\section{ACKNOWLEDGMENT}

We thank the patients, investigators, and study personnel who made this trial possible. A full list of investigators was published ${ }^{1}$. Please note the following corrected names of investigators: Pedro Claudio Miranda Cabezas, MD; Ana Maria Flores Torterolo, MD; Irmgadt Annelise Goecke Sariego, MD; Maria Loreto Massardo Vega, MD; and Juan Pablo Riedemann Gonzalez, MD, MSc. We also thank Michelle L. Perate, MS, and Mary H. Whitman, PhD, (Janssen Biotech Inc.) for their assistance with manuscript preparation and Mahboob U. Rahman (Pfizer Inc.) for his work pertaining to the study design, conduct, and administration.

\section{REFERENCES}

1. Keystone EC, Genovese MC, Klareskog L, Hsia EC, Hall ST, Miranda PC, et al. Golimumab, a human antibody to tumour necrosis factor alpha given by monthly subcutaneous injections, in active rheumatoid arthritis despite methotrexate therapy: The GO-FORWARD Study. Ann Rheum Dis 2009;68:789-96.

2. Keystone E, Genovese MC, Klareskog L, Hsia EC, Hall ST, Miranda PC, et al. Golimumab in patients with active rheumatoid arthritis despite methotrexate therapy: 52-week results of the GO-FORWARD study. Ann Rheum Dis 2010;69:1129-35.

3. Arnett FC, Edworthy SM, Bloch DA, McShane DJ, Fries JF, Cooper NS, et al. The American Rheumatism Association 1987 revised criteria for the classification of rheumatoid arthritis. Arthritis Rheum 1988;31:315-24.

4. Conaghan PG, Emery P, Østergaard M, Keystone EC, Genovese MC, Hsia EC, et al. Assessment by MRI of inflammation and damage in rheumatoid arthritis patients with methotrexate inadequate response receiving golimumab: Results of the GO-FORWARD trial. Ann Rheum Dis 2011;70:1968-74.

5. Felson DT, Anderson JJ, Boers M, Bombardier C, Furst D, Goldsmith C, et al. American College of Rheumatology. Preliminary definition of improvement in rheumatoid arthritis. Arthritis Rheum 1995;38:727-35.

6. Prevoo ML, van 't Hof MA, Kuper HH, van Leeuwen MA, van de Putte LB, van Riel PL. Modified disease activity scores that include twenty-eight-joint counts: Development and validation in a prospective longitudinal study of patients with rheumatoid arthritis. Arthritis Rheum 1995;38:44-8.

7. Wells G, Becker JC, Teng J, Dougados M, Schiff M, Smolen J, et al. Validation of the 28-joint Disease Activity Score (DAS28) and European League Against Rheumatism response criteria based on $\mathrm{C}$-reactive protein against disease progression in patients with rheumatoid arthritis, and comparison with the DAS28 based on erythrocyte sedimentation rate. Ann Rheum Dis 2009;68:954-60.
8. Aletaha D, Ward MM, Machold KP, Nell VP, Stamm T, Smolen JS Remission and active disease in rheumatoid arthritis: Defining criteria for disease activity states. Arthritis Rheum 2005;52:2625-36.

9. Fries JF, Spitz P, Kraines RG, Holman HR. Measurement of patient outcome in arthritis. Arthritis Rheum 1980;23:137-45.

10. Emery P, Fleischmann R, van der Heijde D, Keystone EC, Genovese MC, Conaghan PG, et al. The effects of golimumab on radiographic progression in rheumatoid arthritis: Results of randomized controlled studies of golimumab before methotrexate therapy and golimumab after methotrexate therapy. Arthritis Rheum 2011;63:1200-10.

11. van der Heijde DM, van Leeuwen MA, van Riel PL, Koster AM, van 't Hof MA, van Rijswijk MH, et al. Biannual radiographic assessments of hands and feet in a three-year prospective followup of patients with early rheumatoid arthritis. Arthritis Rheum 1992;35:26-34.

12. National Cancer Institute. The Surveillance, Epidemiology, and End Results (SEER) Database. 2007. [Internet. Accessed March 27, 2013.] Available from: http://seer.cancer.gov/statistics

13. Zhuang Y, Xu Z, Frederick B, de Vries DE, Ford JA, Keen M, et al. Golimumab pharmacokinetics after repeated subcutaneous and intravenous administrations in patients with rheumatoid arthritis and the effect of concomitant methotrexate: an open-label, randomized study. Clin Ther 2012;34:77-90.

14. Emery P, Fleischmann RM, Moreland LW, Hsia EC, Strusberg I, Durez P, et al. Golimumab, a human anti-tumor necrosis factor alpha monoclonal antibody, injected subcutaneously every four weeks in methotrexate-naive patients with active rheumatoid arthritis: Twenty-four-week results of a phase III, multicenter, randomized, double-blind, placebo-controlled study of golimumab before methotrexate as first-line therapy for early-onset rheumatoid arthritis. Arthritis Rheum 2009;60:2272-83.

15. Westhovens R, Yocum D, Han J, Berman A, Strusberg I, Geusens P, et al, on behalf of the START Study Group. The safety of infliximab, combined with background treatments, among patients with rheumatoid arthritis and various comorbidities: A large, randomized, placebo-controlled trial. Arthritis Rheum 2006;54:1075-86.

16. Bongartz T, Sutton AJ, Sweeting MJ, Buchan I, Matteson EL, Montori V. Anti-TNF antibody therapy in rheumatoid arthritis and the risk of serious infections and malignancies: Systematic review and meta-analysis of rare harmful effects in randomized controlled trials. JAMA 2006;295:2275-85.

17. Rahman MU, Strusberg I, Geusens P, Berman A, Yocum D, Baker $\mathrm{D}$, et al. Double-blinded infliximab dose escalation in patients with rheumatoid arthritis. Ann Rheum Dis 2007;66:1233-8.

18. Hsia EC, Schluger N, Cush J, Chaisson RE, Matteson EL, Xu S, et al. Interferon-gamma release assay versus tuberculin skin test across RA, PsA, and AS patients prior to treatment with golimumab, a human anti-TNF antibody. Arthritis Rheum 2012;64:2068-77. 